\title{
A Resection of the Giant First Left Rib Tumor and Chest Wall Reconstruction by Transmanubrial Osteomuscular Sparing Approach
}

\author{
Takanori Ayabe, Masaki Tomita, Hiroki Mori, Eiichi Chosa, Kunihide Nakamura \\ Division of Thoracic and Breast Surgery, Department of Surgery, Faculty of Medicine, University of \\ Miyazaki, Miyazaki, Japan \\ Email: tayabe@med.miyazaki-u.ac.jp
}

Received 23 July 2015; accepted 2 September 2015; published 9 September 2015

Copyright (C 2015 by authors and Scientific Research Publishing Inc.

This work is licensed under the Creative Commons Attribution International License (CC BY).

http://creativecommons.org/licenses/by/4.0/

(c) (i) Open Access

\begin{abstract}
A 64-year-old female had noticed an $11 \times 6 \mathrm{~cm}$ mass growing on her left first rib. We performed a resection of the first and second ribs and a reconstruction of the chest wall. A thoracotomy was performed at the anterolateral second intercostal space. The second rib cartilage was divided at the left parasternum. Based on a transmanubrial osteomuscular sparing approach, the left-upper part of the sternum and the first rib cartilage were both cut at the left clavicular-sternum joint. The posterior parts of the two ribs involving the tumor were resected at the transverse process of the vertebral bone by tearing off the anterior, middle, and posterior scalene muscles, subclavicular artery and vein. The defect size of the thorax was $15 \times 9 \mathrm{~cm}$, which was reconstructed by covering with a polytetrafluoroethylene dual mesh (Dual mesh, Gore tex, $2 \mathrm{~mm}$ ). The major pectoral muscle flap was used to cover the mesh. The postoperative pathological examination diagnosed a poorly differentiated fibrosarcoma. Eventually, she had palliative therapy for the postoperative metastatic chest wall. She died 14 months after the operation.
\end{abstract}

\section{Keywords}

Surgery, Transmanubrial Osteomuscular Sparing Approach, Fibrosarcoma, The First Rib Tumor, Chest Wall Reconstruction

\section{Introduction}

Primary chest wall tumors are uncommon and more than half are malignant, and most of these are the result of

How to cite this paper: Ayabe, T., Tomita, M., Mori, H., Chosa, E. and Nakamura, K. (2015) A Resection of the Giant First Left Rib Tumor and Chest Wall Reconstruction by Transmanubrial Osteomuscular Sparing Approach. Open Journal of Thoracic Surgery, 5, 35-42. http://dx.doi.org/10.4236/ojts.2015.53008 
metastases or direct invasion from adjacent tumors of the thorax, mediastinum, or soft tissue. Primary chest tumors are rare; of these, soft tissue tumors account for roughly 50\%. Chest wall neoplasms, primary and metastatic, can arise from or involve any portion of the thoracic skeleton, including the ribs, sternum, scapulae, and clavicles. The most common site of involvement for all chest wall lesions is the rib cage. Primary lesions of the rib bone are uncommon, but nearly all are malignant [1]. Compared to these lesions, the rib tumors are the most frequently detected and are malignant tumors, however, the first rib tumor is considered to be the rarest location and we found one case report in English [2].

Wide surgical resection is the most effective treatment for the vast majority of chest wall tumors. However, in the case of the first rib tumor, the surgical approach is very complex and difficult. It is considered very difficult to release the anterior part of the first rib from the sternum and the posterior part of the rib from the first transverse process of vertebra in the thorax in order to obtain a sufficient surgical margin of the malignant tumor. The surgery of the cervico-thoracic inlet is a challenge for the thoracic surgeon. The challenge for the surgeon is to improve the extent of the resection without causing major neurologic or vascular damage. Typical operation of the cervicothoracic tumor has used a cervical approach and/or a thoracotomy. Even when using both of these approaches [3], the tumor and vascular dissections are considered difficult, especially regarding the subclavian vessels and the brachiocephalic vein because the clavicle impairs the control of the vascular and neural structures. Due to its anatomical complexity, such as the narrow space between the sternum and clavicle, and the first and second ribs, although which space is forming the entrance of the subclavian artery, brachiocephalic vein, brachial plexus from the thorax, there are various muscle involvements of the anterior, middle, posterior scalene, sternocleidomastoid, and pectoralis major ones. Several authors have described different approaches and with different degrees of invasion to this anatomical area. This challenge is similar to that created by apical bronchopulmonary tumors in adults, which also involve structures of the cervicothoracic junction. The anterior transcervial approach, first described by Cormier in 1970 [4], and then modified by Dartevelle et al. [5], included resection of the medial half of the clavicle. However, deformities and changes in the shoulder morbidity were reported, ruling out this approach in children. In 1997, Grunenwald and Spaggiari [6] and Spaggiari and Pastorino [7] in 1999, proposed a transmanubrial osteomuscular sparing approach for these tumors, permitting excellent exposure of the thoracic and cervical structures [7].

To resect the first and second rib tumors, we performed a transmanubrial approach, a surgical technique which is generally useful for the resection of cervico-thoracic tumors. The transmanubrial osteomuscular approach (TMA) [6] is a reliable alternative to avoid postoperative deformities of the transclavicular technique [5] with excellent results in term of surgical field exposure and extended resections. Besides, the possibility to associate TMA with other "muscle sparing” or "classic" thoracic or laparotomic approaches has improved its versatility.

This report presents our experience in the use of this less invasive cervico-thoracic approach underlying its versatility in approaching different tumors such as the first and second rib ones.

\section{Case Report}

In February, 2009, a 64-year-old female had noticed swelling and the increasing of a mass of the left upper anterior chest wall. She was determined to have a 7-cm tumor in the left first rib by computed tomographic (CT) scanning of the chest at another hospital. She was admitted to our hospital to receive a detailed medical examination in April, 2009. The chest X-ray film showed the mass in the left subclavicular part.

A chest CT scanning revealed an $11 \times 6 \mathrm{~cm}$ tumor growing on the left first rib, which was heterogeneously enhanced and had partly invaded the sternum and showed osteolytic changes (Figure 1(a)-(c)). Three-dimensional CT scanning revealed the exact anatomical location and relation of the sternum, ribs, clavicular, and subclavicular vessels to the tumor (Figure 2). Based on the CT-guided needle biopsy of the tumor, the diagnosis of a malignant spindle cell tumor was made. Position emission topography revealed an abnormal accumulation of the rib tumor (SUV max early: 10.0, delay: 12.7) suspected to be a malignant.

In May, 2009, we performed a surgical resection of the giant tumor of the first rib by combined removal with the first and second ribs and partial resection of the sternum (Figure 3). Using the median skin incision with the left collar, the left major pectoral muscle flap was made. As the tumor had invaded the minor pectoral muscle, it was partly resected. A thoracotomy was performed at the second intercostal space as pulmonary invasion and dissemination in the thoracic cavity could not be observed by video thoracoscopicy, however, the tumor was suspected to invade the first intercostal space. By thoracotomy at the second intercostal space, the first and 


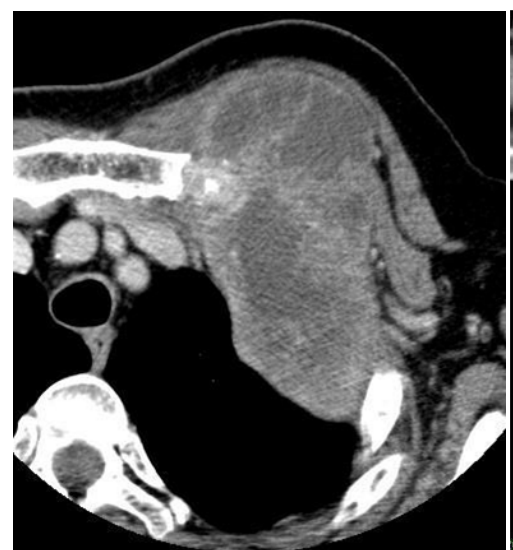

(a)

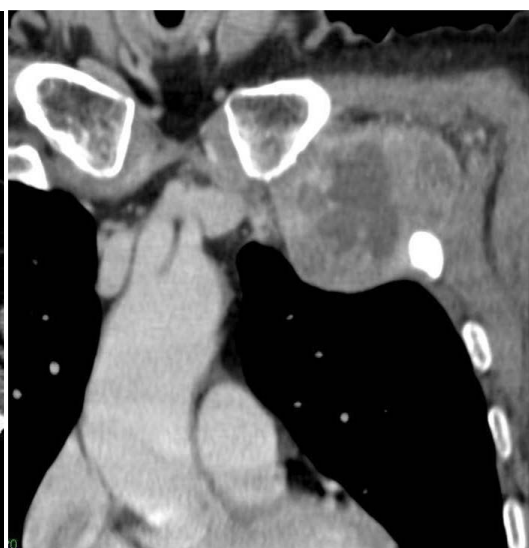

(b)

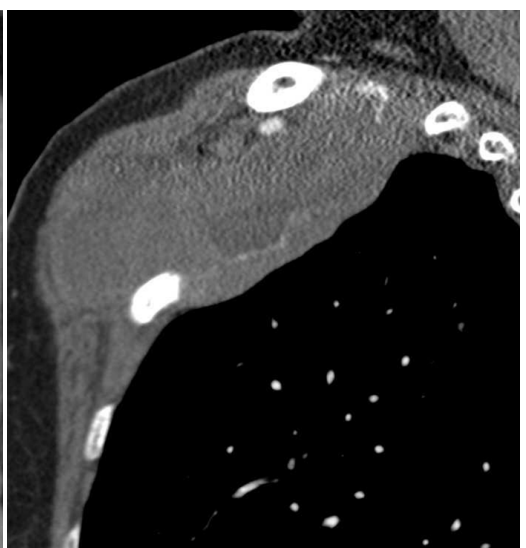

(c)

Figure 1. A chest CT scanning revealed the $11 \times 6 \mathrm{~cm}$ tumor growing on the left first rib with osteolytic changes, which had partly invaded the sternum and involved the second rib.

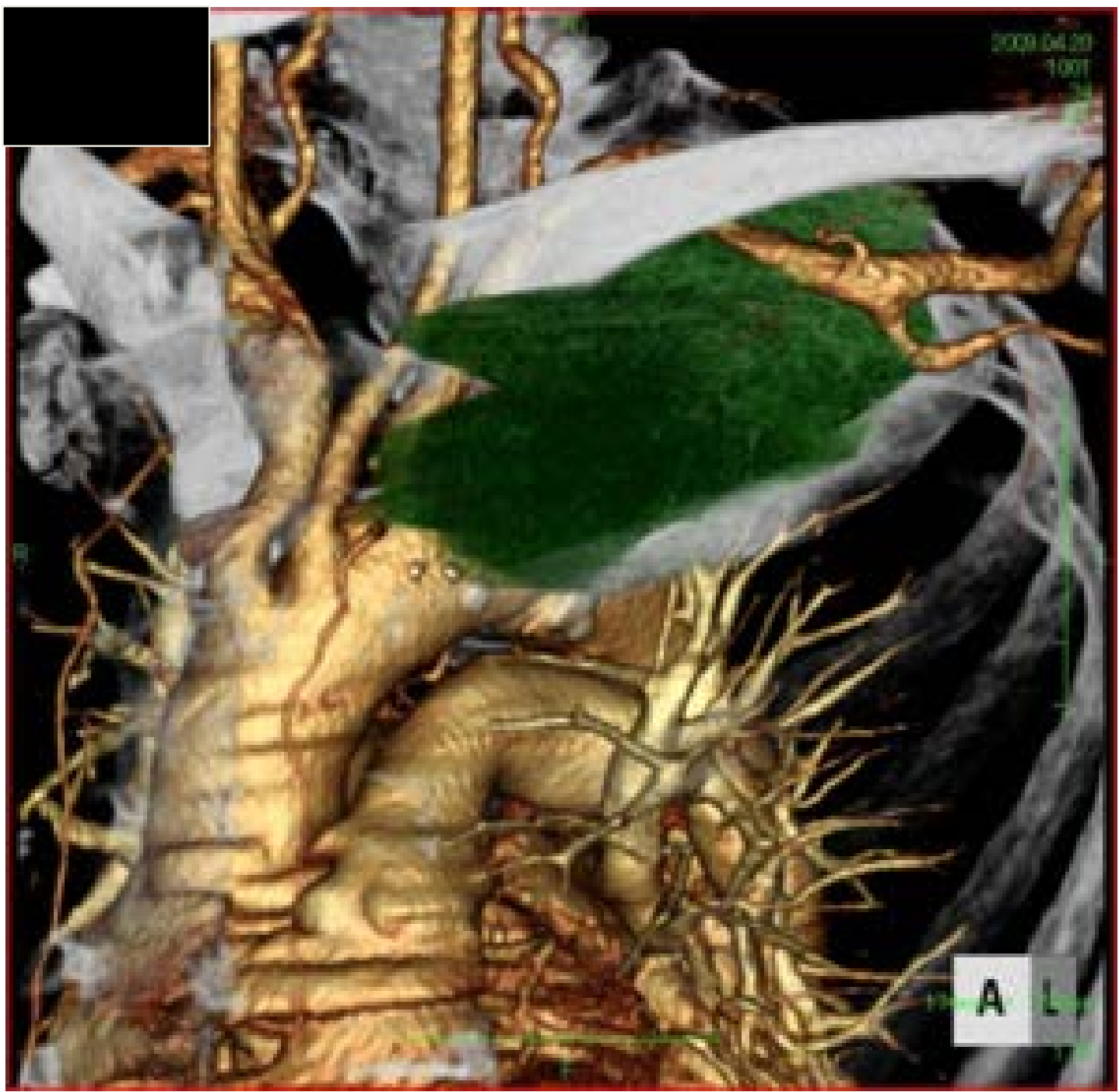

Figure 2. Three-dimensional CT scanning revealed the exact anatomical location and relation of the sternum, ribs, clavicular, and subclavicular vessel to the tumor. 


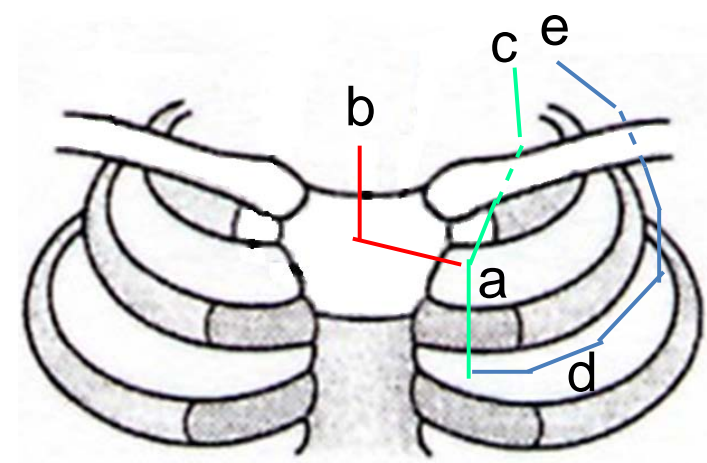

Figure 3. The second rib cartilage was cut at the left parasternum (a). The left-upper part of the sternum (b) and the first rib cartilage (c) were both cut without dividing at the left clavicular-sternum joint by the transmanubrial osteomuscular sparing approach (b) (c). Both ribs were resected at the second intercostal space (d) and released at the transverse process of the vertebral bone by tearing off the anterior, middle, and posterior scalene muscles (e).

second ribs were planned to be removed. After division of the left mammary artery and veins, the second rib cartilage was cut at the left parasternum. The left-upper part of the sternum and the first rib cartilage were both cut without dividing at the left clavicular-sternum joint by a transmanubrial osteomuscular sparing approach. Both ribs were resected at the second intercostals pace and released at the transverse process of the vertebral bone by tearing off the anterior, middle, and posterior scalene muscles, and subclavicular artery and vein. The transmanubrial osteomuscular part was re-fixed to the sternum with stainless steel wire. The defect size of chest wall was measured to be $15 \times 9 \mathrm{~cm}$ in size (Figure 4(a)), which was reconstructed by covering with polytetrafluoroethylenedual mesh (Dual mesh, Gore tex, $2 \mathrm{~mm}$ ) (Figure 4(b)). The major pectoral muscle flap was covered in the reconstructed chest wall.

The resected tumor is shown in Figure 5(a). The postoperative findings displayed a proliferation of oval to spindle-shaped tumor cells with tapered nuclei, arranged in fascicles, in vague storiform or in haphazard fashion (Figure 5(b)). Focally, the tumor cells have an eosinophilic cytoplasm. Hemangiopericytomatous vessels were prominent throughout the tumor. Mitotic figures were frequently seen and a significant tumor necrosis was also observed. Immunohistochemically, the spindle tumor cells were focally positive for HHF-35, but negative for alpha-smooth muscle actin, desmin, and h-caldesmon. This feature was suggestive of a poorly differentiated fibrosarcoma. Eventually, the postoperative pathological examination diagnosed a poorly differentiated fibrosarcoma.

The postoperative clinical course was not eventful. However, postoperatively, a chest CT scanning revealed several small round masses in the right lung field, which were suspected to be multiple pulmonary metastases. In July, 2009, she received chemotherapy which was a regimen of CDDP (on day1) + adriamycin (on day1, 2) + caffeine for the soft tissue tumor. The chemotherapy was performed for 5 cycles until December, 2009. Some of the multiple pulmonary metastatic masses had shrunk. In December, 2010, radiofrequency ablation therapy was performed for two metastatic pulmonary masses in the right S2 and S3. In January, 2010, a bone scintinography disclosed a suspected metastasis of the right sixth rib bone.

In February, 2010, she received irradiation therapy (3.0 Gy/day, total $36.0 \mathrm{~Gy} / 12$ days) for the $6^{\text {th }}$ rib metastasis and there was no adverse event as the metastatic chest wall tumor had shrunk.

However, in May, 2010, a chest X-ray showed a mass of $74 \times 85 \mathrm{~mm}$ in size in the right lung field which CT scanning identified as a new metastasis in the S2 lesion. As the pulmonary tumor had increased in size, she received a second irradiation therapy for the right chest wall recurrence (2.0 Gy/day, total 50 Gy/25 days). Abdominal CT scanning revealed an intraabdominal metastasis such as a metastatic adrenal mass. Although she had palliative therapy after the radiation therapy two months later, she was dead postoperative 14 months later.

\section{Discussion}

Primary chest wall tumors are uncommon, accounting for only $0.04 \%$ of all new cancers diagnosed and $5 \%$ of 


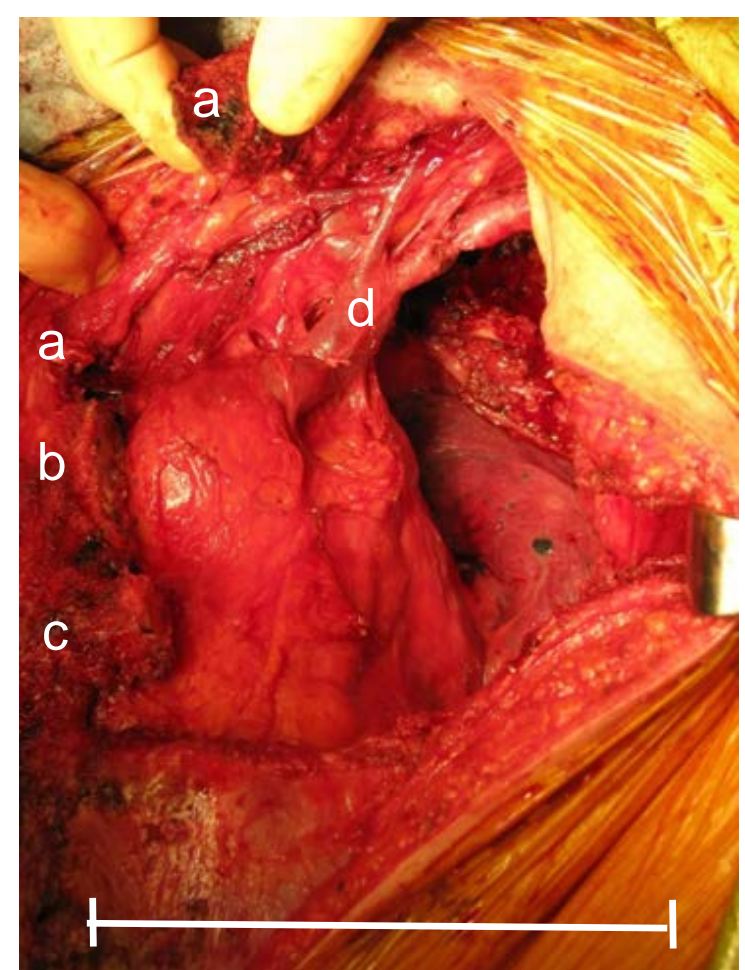

(a)

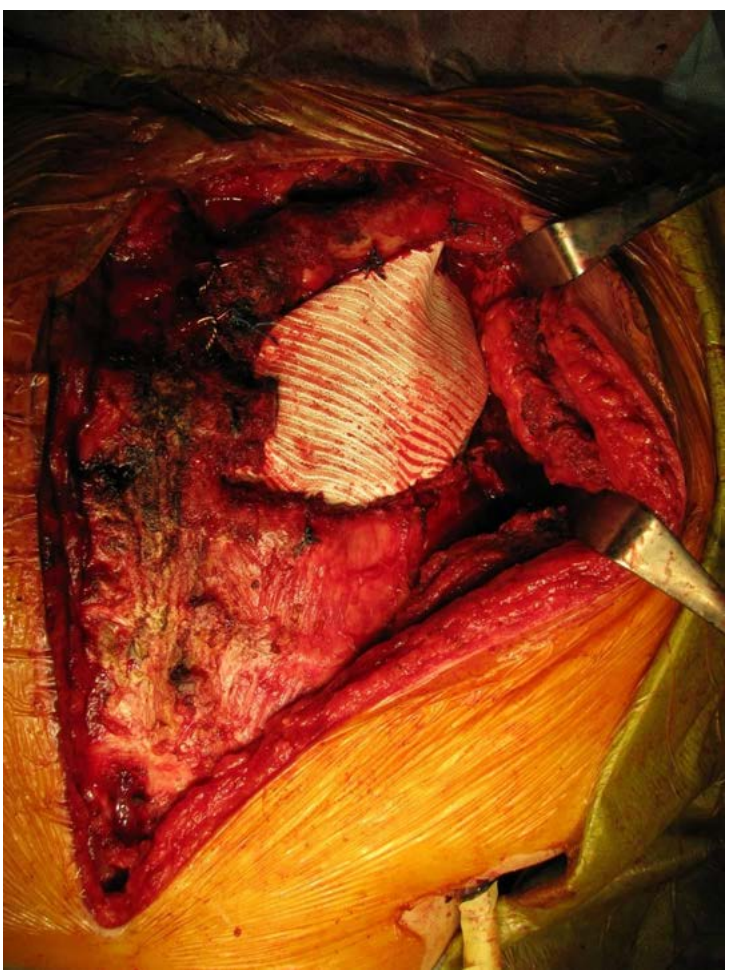

(b)

Figure 4. (a) After the resection of the first and second ribs and tumor by the transmanubrial osteomuscular sparing approach, the defect size of the chest wall measured $15 \times 9 \mathrm{~cm}$ in size. A white scale bar of $10 \mathrm{~cm}$ is located at the bottom of the figure. a: the left-upper part of the sternum with clavicular; b: the first rib cartilage was cut at the left parasternum; c: the second rib cartilage was cut at the left parasternum; d: subclavicular vein. (b) The defect of the thorax was reconstructed by covering with polytetrafluoroethylene dual mesh (Dual mesh, Gore tex, $2 \mathrm{~mm}$ ). Major pectoral muscle flap covered the reconstructed chest wall.

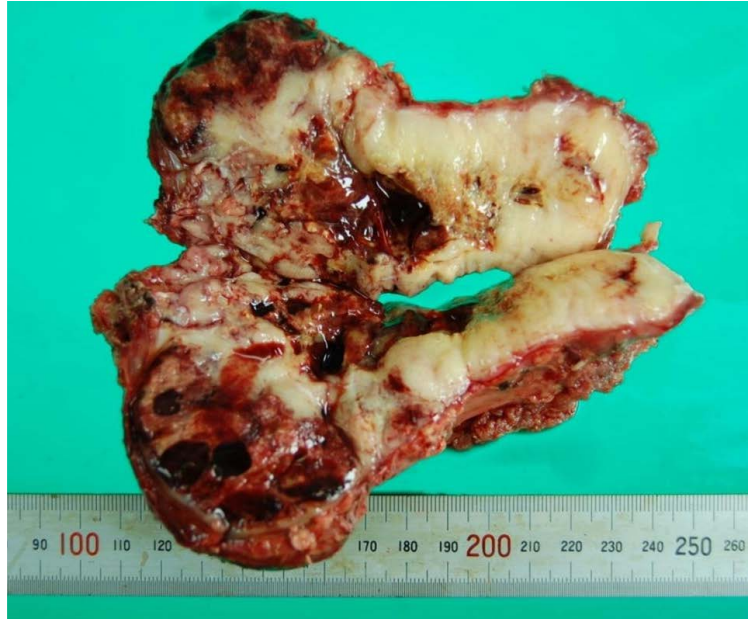

(a)

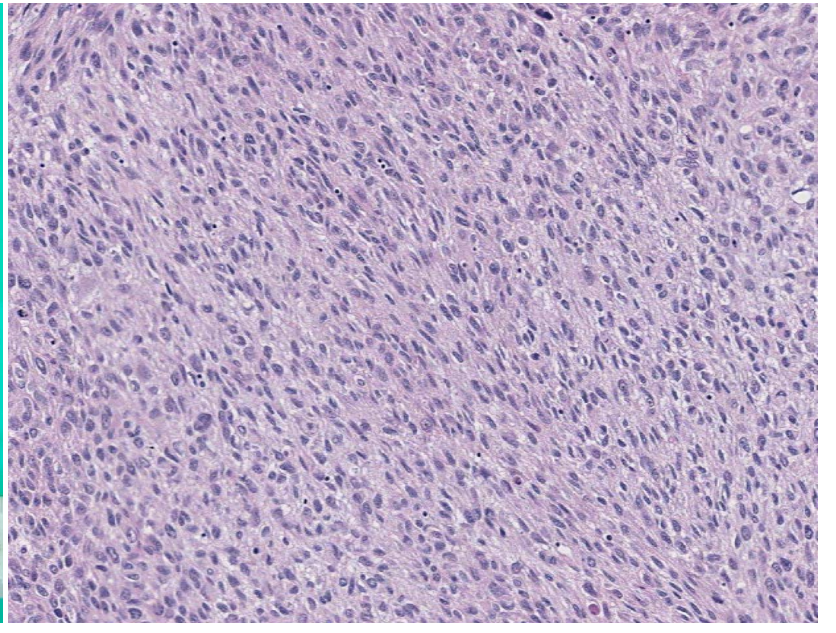

(b)

Figure 5. (a) The cut-surface of the resected rib tumor. (b) The postoperative pathology diagnosed with poorly differentiated fibrosarcoma.

all thoracic neoplasms [8]-[10]. Primary tumor of the rib comprises 5\% - 7\% of all primary bone neoplasms, but make up 50\% of bony malignant tumors and the majority of benign tumors of the chest wall [9] [11]. An incidence of rib tumors is less than $1 \%$ in the population [8]-[10]. 
Primary sarcomas of the thorax are classified according to their histologic features and constitute a large group of tumors that occur in the lung, mediastinum, pleura, and chest wall. Angiosarcoma, leiomyosarcoma, rhabdomyosarcoma, and mesothelioma (sarcomatoid variant) are the most common primary intrathoracic sarcomas. Ewing sarcoma, primitive neuroectodermal tumor, chondrosarcoma, malignant fibrous histiocytoma, osteosarcoma, synovial sarcoma, and fibrosarcoma usually arise in the chest wall [12].

The present case was finally diagnosed as a fibrosarcoma by the postoperative pathological close examination of the surgical resected specimen. Fibrosarcomas are potentially highly malignant tumors originating from the mesenchymal cells and occurring in various anatomic sites including the lung and chest wall [13]-[15]. In the chest, the fibrosarcoma must be differentiated from fibrous mesotheliomas, malignant fibrous tumors of the pleura, and other sarcomas, such as myxofibrosarcoma, synovial sarcoma, or nerve sheath sarcoma [13] [14]. Mesothelioma always stains positive for keratin, whereas fibrosarcomas, fibrous tumors of the pleura, and most other sarcomas remain negative for keratin and stain positive for vimentin [16]. Additional markers, such as S-100 protein, desmin, or alpha-smooth muscle actin allow further differentiation between the different types of sarcomas [17].

In the treatment of primary soft tissue sarcomas, chemotherapy and radiotherapy are less effective, thus the appropriate surgery is needed. Extensive resection with a sufficient margin $(3-4 \mathrm{~cm})$ is considered as first-line therapy [18]. Surgery is considered the best option for most malignant tumors of the chest wall.The published case reports and small series on primary soft tissue sarcomas involving the chest wall provide a limited perspective on which to base one's evaluation and management [19]-[22].

Wide excision with clear margins is very important for long-term survival [22]. A 2-cm margin is advocated by Graeber et al. [23] for low-grade tumors, and a 4-cm margin for high-grade sarcomas. To achieve local control, an adequate resection margin is indispensable, and therefore, a thoracotomy associated with rib resection or flap transfer for extensive skin defects may be required in such cases. Depending on the onset location, however, it may be difficult to have a sufficient safety margin. In the present case, the medial margin of the thoracic cavity was diagnosed as a marginal margin, and it will be necessary to carefully follow the patient, however, there was no local recurrence but distant metastasis. A case of the resection of a chondrosarcoma arising in the right first rib was reported [24].

Chest wall tumor resection is possible with perioperative mortality from $0 \%$ to $4.5 \%$ [25]-[27]. Loss of more than 4 consecutive ribs or defects in the lateral chest wall larger than $5 \mathrm{~cm}$ necessitates skeletal stabilization to avert a flail chest deformity. The existing options include either autogenous or alloplastic reconstruction. Many different types of flaps, either pedicled or free, have been described for autogenous reconstruction of the chest wall deficiency. Pedicle muscle and myocutaneous options include the pectoralis major, latissimusdorsi, abdominal rectus, external oblique and trapezius flaps [28]. The use of alloplastic materials in chest wall reconstruction are based on convenience, reliability and ease of application of the synthetic materials. Alloplastic materials include non-absorbable synthetic woven meshes; i.e., polypropylene, polyester and polytetrafluoroethylene soft tissue patches or, more recently, knitted meshes [28]. In the present case, we used a dual mesh of polytetrafluoroethylene, which was used for covering the defected apex thorax without narrowing the inlet of the brachiocephalic artery and vein.

The thoracic inlet and adjacent structures may be involved in different clinical settings, including superior sulcus tumors ('anterior Pancoast tumors'), neurogenic tumors, metastatic lesions, verterbral and first rib tumors [2]. The surgical approach to this area is complex, with different degrees of invasiveness [2]. Grunenwald and Spaggiari [6] proposed a transmanubrial osteomuscular sparing approach without resection of the clavicle for removing the anterior Pancoast tumors.

The transmanubrial osteomuscular sparing approach (TMA) has been proposed for the treatment of an apical chest tumor to allow for a safer subclavian artery control with a less invasive procedure for the patient [29]. The technique combines the antero-lateral muscle-sparing thoracotomy with TMA for lung cancer patients in whom extended resection of the cervico-thoracic structures as well as anatomic lung resection and radical lymph nodes dissection are required [29]. TMA offers wide surgical exposure with the possibility to perform en-bloc extended resection with no osteo-muscular sacrifices associated with good functional outcome [29]. Its versatility has progressively increased surgical indications compared to the initially published applications [6].

For the apical chest tumor, Grunenwald [30] suggested performing an anatomic upper lobectomy through the TMA after having resected the first and second ribs. Even though the upper lobectomy may be feasible using the TMA or transclavicular approaches alone, a radical lymph nodes dissection is certainly not possible through only these cervical approaches [29]. Moreover, in the case of an extensive en bloc chest wall resection, hilar node 
Table 1. Mini review of clinical features of reconstruction of chest wall after resection of fibrosarcoma.

\begin{tabular}{|c|c|c|c|c|c|c|c|c|c|c|c|c|}
\hline $\begin{array}{l}\text { Case } \\
\text { No. }\end{array}$ & References & years & Age & Gender & $\begin{array}{l}\text { Tumor } \\
\text { Location }\end{array}$ & Resection & $\begin{array}{l}\text { Defect size } \\
\left(\mathrm{cm}^{2}\right)\end{array}$ & $\begin{array}{l}\text { Prosthetic } \\
\text { material }\end{array}$ & RT & CT & Outcome & $\begin{array}{l}\text { Survival } \\
\text { (months) }\end{array}$ \\
\hline 1 & [19] & 2005 & 40 & $\mathrm{~F}$ & dorsal & chest wall, lung & 100 & Marlex & & & NED & 144 \\
\hline 2 & [19] & 2005 & 28 & $\mathrm{~F}$ & anterior & chest wall & 120 & Gore & & & NED & 84 \\
\hline 3 & [19] & 2005 & 73 & M & lateral & chest wall & 250 & Vicryl & & & NED & 120 \\
\hline 4 & [19] & 2005 & 61 & $\mathrm{~F}$ & anterior & sternum, lung & 1050 & Marlex & & post & DOD & 35 \\
\hline 5 & [19] & 2005 & 51 & M & anterior & sternum, lung & 220 & Sandwitch & & & NED & 160 \\
\hline 6 & [31] & 2001 & 61 & M & anterior & chest wall, lung & - & Sandwitch & post & & NED & 60 \\
\hline 7 & Our case & 2015 & 64 & $\mathrm{~F}$ & 1st-rib & chest wall & 135 & Gore & & post & DOD & 14 \\
\hline
\end{tabular}

NED: no evidence of disease; DOD: dead of disease; RT: Radiotherapy; CT: Chemotherapy.

dissection might be difficult and dangerous through TMA alone, however, for our case of the first and the second rib tumor, a resection and reconstruction of the apical thorax is needed, so this TMA approach should only be effective to expose the appropriate operative field because the hilar lymph node dissection is not required.

Lastly, we showed a mini review of case reports on clinical features of the resected fibrosarcoma of the chest wall and lung in Table 1.

\section{Conclusion}

We consider taht the TMA accesses a valuable technique for the surgical treatment of the first left rib tumor of the cervico-thoracic inlet. The cosmetic and functional results are good without any limitation. The exposure of the operative field of the cervico-thoracic inlet is excellent. The removal of the tumor of the first and the second ribs, which are very deeply located in the inlet, is possible by this approach, without adding a posterior thoracotomy.

\section{References}

[1] Dahlin, D.C. and Unni, K.K. (1986) Bone Tumors: General Aspects and Data on 8542 Cases. Charles C. Thomas, Springfield.

[2] Di Rienzo, G., Surrente, C., Lopez, C. and Urgese, A.L. (2010) Transmanubrial Osteomuscular Sparing Approach: Different Indications. Interactive Cardiovascular and Thoracic Surgery, 11, 482-484. http://dx.doi.org/10.1510/icvts.2010.243238

[3] Pranikoff, T., Hirschl, R.B. and Schnaufer, L. (1995) Approach to Cervicothoracic Neuroblastomas via a Trap-Door Incision. Journal of Pediatric Surgery, 30, 546-548. http://dx.doi.org/10.1016/0022-3468(95)90127-2

[4] Cormier, J.M. (1970) Voie, d'abord and de Partere sous-claviere. In: Patel, J. and Leger, L., Eds., Nouveau traite de technique Chirugicale. Tume V, Masson et Cie, Paris, 107-140.

[5] Dartevelle, P.G., Chapelier, A.R., Macchiarini, P., Lenot, B., Cerrina, J., Ladurie, F.L., Parquin, F.J. and Lafont, D. (1993) Anterior Transcervical-Thoracic Approach for Radical Resection of Lung Tumors Invading the Thoracic Inlet. The Journal of Thoracic and Cardiovascular Surgery, 105, 1025-1034.

[6] Grunenwald, D. and Spaggiari, L. (1997) Transmanubrial Osteomuscular Sparing Approach for Apical Chest Tumors. The Annals of Thoracic Surgery, 63, 563-566. http://dx.doi.org/10.1016/S0003-4975(96)01023-5

[7] Spaggiari, L. and Pastorino, U. (1999) Transmanubrial Approach with Antero-Lateral Thoracotomy for Apical Chest Tumor. The Annals of Thoracic Surgery, 68, 590-593. http://dx.doi.org/10.1016/S0003-4975(99)00630-X

[8] Shah, A.A. and D’Amico, T.A. (2010) Primary Chest Wall Tumors. Journal of the American College of Surgeons, 210, 360-366. http://dx.doi.org/10.1016/j.jamcollsurg.2009.11.012

[9] Smith, S.E. and Keshavjee, S. (2010) Primary Chest Wall Tumors. Thoracic Surgery Clinics, 20, 495-507. http://dx.doi.org/10.1016/j.thorsurg.2010.07.003

[10] Faber, L.P., Somers, J. and Templeton, A.C. (1995) Chest Wall Tumors. Current Problems in Surgery, 32, 661-747. http://dx.doi.org/10.1016/s0011-3840(05)80007-3 
[11] Hughes, E.K., James, S.L., Butt, S., Davies, A.M. and Saifuddin, A. (2006) Benign Primary Tumours of the Ribs. Clinical Radiology, 61, 314-322. http://dx.doi.org/10.1016/j.crad.2005.12.005

[12] Gladish, G.W., Sabloff, B.M., Munden, R.F., Truong, M.T., Erasmus, J.J. and Chasen, M.H. (2002) Primary Thoracic Sarcomas. Radiographics, 22, 621-637. http://dx.doi.org/10.1148/radiographics.22.3.g02ma17621

[13] Régnard, J.F., Icard, P., Guibert, L., de Montpreville, V.T., Magdeleinat, P. and Levasseur, P. (1999) Prognostic Factors and Results after Surgical Treatment of Primary Sarcomas of the Lung. The Annals of Thoracic Surgery, 68, 227-231. http://dx.doi.org/10.1016/S0003-4975(99)00398-7

[14] Bacha, E.A., Wright, C.D., Grillo, H.C., Wain, J.C., Moncure, A., Keel, S.B., Donahue, D.M. and Mathisen, D.J. (1999) Surgical Treatment of Primary Pulmonary Sarcomas. European Journal of Cardio-Thoracic Surgery, 15, 456-460. http://dx.doi.org/10.1016/S1010-7940(99)00045-7

[15] Gordon, M.S., Hajdu, S.I., Bains, M.S. and Burt, M.E. (1999) Soft Tissue Sarcomas of the Chest Wall. Results of Surgical Resection. The Journal of Thoracic and Cardiovascular Surgery, 101, 843-854.

[16] de Perrot, M., Kurt, A.M., Robert, J.H., Borisch, B. and Spiliopoulos, A. (1999) Clinical Behavior of Solitary Fibrous Tumors of the Pleura. The Annals of Thoracic Surgery, 67, 1456-1459. http://dx.doi.org/10.1016/S0003-4975(99)00260-X

[17] Keel, S.B., Bacha, E., Mark, E.J., Nielsen, G.P. and Rosenberg, A.E. (1999) Primary Pulmonary Sarcoma: A Clinicopathologic Study of 26 Cases. Modern Pathology, 12, 1124-1131.

[18] McAfee, M.K., Pairolero, P.C., Bergstralh, E.J., Piehler, J.M., Unni, K.K., McLeod, R.A., Bernatz, P.E. and Payne, W.S. (1985) Chondrosarcoma of the Chest Wall: Factors Affecting Survival. The Annals of Thoracic Surgery, 40, 535-541. http://dx.doi.org/10.1016/S0003-4975(10)60344-X

[19] Pfannschmidt, J., Geisbüsch, P., Muley, T., Dienemann, H. and Hoffmann, H. (2006) Surgical Treatment of Primary Soft Tissue Sarcomas Involving the Chest: Experiences in 25 Patients. The Thoracic and Cardiovascular Surgeon, 54, 182-187. http://dx.doi.org/10.1055/s-2005-872973

[20] Walsh, G.L., Davis, B.M., Swisher, S.G., Vaporciyan, A.A., Smythe, W.R., Willis-Merriman, K., Roth, J.A. and Putnam Jr., J.B. (2001) A Single-Institutional, Multidisciplinary Approach to Primary Sarcomas Involving the Chest Wall Requiring Full-Thickness Resections. The Journal of Thoracic and Cardiovascular Surgery, 121, 48-60. http://dx.doi.org/10.1067/mtc.2001.111381

[21] Incarbone, M. and Pastorino, U. (2001) Surgical Treatment of Chest Wall Tumors. World Journal of Surgery, 25, 218230. http://dx.doi.org/10.1007/s002680020022

[22] King, R.M., Pairolero, P.C., Trastek, V.F., Piehler, J.M., Payne, W.S. and Bernatz, P.E. (1986) Primary Chest Wall Tumors: Factors Affecting Survival. The Annals of Thoracic Surgery, 41, 597-601. http://dx.doi.org/10.1016/S0003-4975(10)63067-6

[23] Graeber, G.M., Snyder, R.J., Fleming, A.W., Head, H.D., Lough, F.C., Parker, J.S., Zajtchuk, R. and Brott, W.H. (1982) Initial and Long-Term Results in the Management of Primary Chest Wall Neoplasms. The Annals of Thoracic Surgery, 34, 664-673. http://dx.doi.org/10.1016/S0003-4975(10)60906-X

[24] Kitada, M., Ozawa, K., Sato, K., Hayashi, S. and Sasajima, T. (2010) Resection of a Chondrosarcoma Arising in the Right First Rib: A Case Report. Annals of Thoracic and Cardiovascular Surgery, 16, 118-121.

[25] McCormack, P., Bains, M.S., Beattie Jr., E.J. and Martini, N. (1981) New Trends in Skeletal Reconstruction after Resection of Chest Wall Tumors. The Annals of Thoracic Surgery, 31, 45-52. http://dx.doi.org/10.1016/S0003-4975(10)61315-X

[26] Graeber, G.M.J.D. and Pairolero, P.C. (1995) Primary Neoplasm. In: Pearson, G.F.D.J., Hiebert, C.A., Ginsberg, R.J., McKneally, M.F. and Urschel, H., Eds., Thoracic Surgery, Churchill Livingstone, Philadelphia, 1237-1251.

[27] Arnold, P.G. and Pairolero, P.C. (1996) Chest-Wall Reconstruction: An Account of 500 Consecutive Patients. Plastic \& Reconstructive Surgery, 98, 804-810. http://dx.doi.org/10.1097/00006534-199610000-00008

[28] Sakellaridis, T., Gaitanakis, S. and Piyis, A. (2014) Rib Tumors: A 15-Year Experience. General Thoracic and Cardiovascular Surgery, 62, 434-440. http://dx.doi.org/10.1007/s11748-014-0387-9

[29] Spaggiari, L., Calabrese, L., Gioacchino, G. and Pastorino, U. (1999) Cervico-Thoracic Tumors Resection through Transmanubrial Osteomuscular Sparing Approach. European Journal of Cardio-Thoracic Surgery, 16, 564-567. http://dx.doi.org/10.1016/S1010-7940(99)00311-5

[30] Grunenwald, D. (1998) Hemivertebrectomy for Apical Chest Tumors: Is the Risk Justified? [Reply to Letter]. The Annals of Thoracic Surgery, 65, 1516-1517.

[31] Fischer, S., de Perrot, M., Sekine, Y. and Keshavjee, S. (2001) Long-Term Survival after Multiple Resections of a Fibrosarcoma Involving the Lung and Chest Wall. European Journal of Cardio-Thoracic Surgery, 20, 421-423. http://dx.doi.org/10.1016/S1010-7940(01)00806-5 